\title{
Mineralogy and thermal expansion study of mullite-based ceramics synthesized from coal fly ash and aluminum dross industrial wastes
}

\begin{abstract}
Mullite-based ceramics were produced entirely from industrial wastes. Aluminum dross (AD) is a waste product produced in secondary aluminum refining, and coal fly ash (CFA) which is a waste generated by coal-fired power plant. Both were mixed together in different weight ratio, subsequently compacted and sintered. The effects of the sintering temperature, acid leaching and $\mathrm{A} 12 \mathrm{O} 3 / \mathrm{SiO} 2$ ratio on the chemical, physical, thermal expansion properties of the samples were characterized in detail. The results showed that appropriate mixing ratio and acid leaching had positive effects on the mineralogy, crystallinity, and macromorphology of sintered samples. At sintering temperature of $1500^{\circ} \mathrm{C}$, high mullite content ceramics with good crystallinity were produced. The resultant ceramics exhibited excellent thermal expansion properties with coefficient of thermal expansion (CTE) values ranging from 4.0 to $5.9 \times 10-6{ }^{\circ} \mathrm{C}-1$ (average between $30^{\circ} \mathrm{C}$ and $1000^{\circ} \mathrm{C}$ ). This study demonstrated that the production of mullite-based ceramics using entirely $\mathrm{CFA}$ and $\mathrm{AD}$ was feasible.
\end{abstract}

